Revista Iberoamericana, Vol. LXXI, Núm. 210, Enero-Marzo 2005, 11-19

\title{
MAPAS E ITINERARIOS EN LOS IMAGINARIOS FEMENINOS LATINOAMERICANOS
}

\author{
POR \\ Alicia Ortega \\ Universidad Andina Simón Bolívar, Quito \\ Susana Rosano \\ University of Pittsburgh
}

No se nace mujer: llega una a serlo

Simone de Beauvoir

En su bello libro The Gender of Modernity, Rita Felski recuerda que la modernidad puede ser leída como una categoría de análisis cultural. Lo moderno no sólo se refiere a un fenómeno socio-histórico sino a experiencias de temporalidad y conciencia, de autorreflexividad, donde las interferencias del género pueden ser analizadas en el contexto de sus diferentes narrativas. Felski contrapesa en este sentido dos interpretaciones de la modernidad: por un lado, la de Marshall Berman en Todo lo sólido se desvanece en el aire, donde se organiza un relato a partir de la norma de lo masculino. En su lectura del Fausto y en su evocación del flaneur baudelairiano, Berman asimila lo masculino con lo moderno y lo femenino con la tradición, y adscribe así a una lectura paternalista de la modernidad. Pero Feslki contrapone a este libro Women in Modern Drama: Freud, Feminism and European Theater at the Turn of the Century, de Gail Finney, donde la psicología y la sexualidad femeninas son centrales en las representaciones de la modernidad de la Europa de fin de siglo. En este sentido, si el feminismo expresa una rebelión contra las históricas condiciones de opresión de las mujeres, la histeria puede ser interpretada como un acto de resistencia ante la sociedad moderna, pasiva y autodestructiva. De esta manera, a la lectura que hace Berman del Fausto como un nuevo Prometeo, se contrapone la de Lulú metamorfoseada en una moderna Pandora.

$\mathrm{Al}$ analizar los modos en que la modernización ha sido representada en los últimos siglos en América Latina, es posible auscultar las diferentes negociaciones de las mujeres con su medio social, y trabajar a partir de allí sus ambigüedades y contradicciones. Leer las marcas de género en la modernidad implica entonces reconstruir las representaciones y autorrepresentaciones con que las mujeres se inscriben como sujetos en la sociedad de la época. Pensado como una categoría que intercepta a la modernidad, el género puede ser leído como una forma de experiencia social pero también como un principio de análisis para el desmontaje de una determinada época, donde su punto central lo constituirían los efectos del ejercicio de poder en una sociedad determinada. Desde esta perspectiva, Michel Foucault reconoce que la sexualidad -que a primera vista se nos aparece como natural, privada- en realidad está construida culturalmente de acuerdo a las metas 
hegemónicas de las clases dominantes. Y es en este sentido en que ubica a las tecnologías de la sexualidad dentro de las del ser, como un "set de técnicas para maximizar la vida" (127), que fueron desarrolladas por la burguesía desde fines del siglo xviı y contribuyeron al sostenimiento de su hegemonía.

De esta manera el género no se constituye como una propiedad de los cuerpos o algo originalmente existente en los seres humanos, sino como el conjunto de los efectos producidos en éstos, en los comportamientos y relaciones sociales, a partir del despliegue de una compleja tecnología política disciplinadora o biopolítica, de acuerdo al término acuñado por Foucault. Esta tecnología hace de la sexualidad y del género no sólo una preocupación secular sino también del Estado, que ejercita sus efectos represivos, de control, sobre cuatro objetos privilegiados de conocimiento: la sexualidad de los chicos y del cuerpo femenino, el control de la procreación y la psiquiatrización de los procesos sexuales anómalos como perversiones. Estos dispositivos de control están sostenidos por el Estado, institución moderna por excelencia, y son reproducidos al interior de cada subjetividad en primera instancia por la familia.

En "The Technology of Gender”, Teresa de Lauretis analiza los principios de Michel Foucault pero reconoce que la teoría feminista del aparato cinematográfico, influida por Louis Althusser y Jacques Lacan, es más productiva a la hora de estudiar no sólo cómo una determinada tecnología construye la representación del género sino también cómo ella es absorbida por cada uno de los individuos a los que esa tecnología va dirigida. Es decir, cómo esas estructuras de dominación se perpetúan a partir de los procesos de reproducción (familia, escuela, Estado). Desde allí, la teoría cinematográfica feminista construye la figura del espectador como un gendered concept. Esta construcción al interior de un proceso de representación hegemónico, culturalmente pautada, es precisamente lo que pretende desmontar, desfamiliarizar, historizar, la crítica feminista.

El género entonces puede ser leído como una división de los sexos socialmente impuesta, producto de las relaciones de la sexualidad al exterior de sí misma. Los signos "hombre” y “mujer” son construcciones discursivas que el lenguaje de la cultura imprime en los cuerpos, ocultando su carácter de construcción identitaria bajo una superficie de naturalidad y a partir de una metafísica de la sustancia (Butler). Al oponerse a la posición feminista humanista que considera al género como un "atributo" del ser humano caracterizado esencialmente como una sustancia previa al género mismo, Butler plantea como punto de partida para una teoría social del género las posiciones antropológicas que entienden a éste como "una relación entre sujetos socialmente constituidos en contextos específicos" (43).

En un texto hoy ya clásico, "El tráfico de las mujeres: notas sobre la economía política del sexo”, la antropóloga Gayle Rubin se pregunta cuáles son las relaciones en las que una hembra de la especie se convierte en oprimida, ya sea como esposa, doméstica, mercancía, conejita de Playboy o prostituta. Y, a partir de la puntillosa lectura de la obra de Claude Levi Strauss y de Sigmund Freud, la antropóloga desmantela un aparato social sistemático que "emplea mujeres como materia prima y modela mujeres domesticadas como producto" (96). Entender la naturaleza y génesis de la opresión y de la subordinación social de las mujeres implica entonces escrutar la economía política del sexo, erigida sobre la heterosexualidad obligatoria y la apropiación de la fertilidad femenina por parte de los 
hombres. Dicha política fija un orden jerárquico basado en los géneros que representan, a su vez, una división de los sexos socialmente impuesta y el sistema de relaciones entre ellos.

Rubin registra que el capitalismo es ya heredero de una larga tradición de opresión de las mujeres, y se enfoca en la lectura de Las estructuras sociales del parentesco y "La familia”, de Claude Levi Strauss, al reconocer que en estos se entiende explícitamente al parentesco como una imposición de la organización cultural sobre los hechos de la procreación biológica. La relación total de intercambio que constituye el matrimonio no se establece entre un hombre y una mujer sino entre dos grupos de hombres, donde la mujer figura sólo como uno de los objetos del intercambio. Para Lévi-Strauss "las mujeres son como las palabras, que están mal empleadas cuando no son “comunicadas’ e intercambiadas” (132). De esta manera, las transacciones del matrimonio son una rica fuente de datos para saber quién tiene derechos sobre quién. Los sistemas de parentesco no sólo intercambian mujeres, sino acceso sexual, situación genealógica, nombres de linajes y antepasados, derechos y personas (hombres, mujeres y niños) en sistemas concretos de relaciones sociales.

En ninguna parte están mejor documentados los efectos que tienen sobre las mujeres los sistemas sociales dominados por los hombres que en la literatura clínica del psicoanálisis. Gayle lee la narrativa del complejo de Edipo freudiano como una teoría de la sexualidad en la sociedad humana, que es más el resultado de un desarrollo psíquico que biológico. Para el psicoanálisis, a partir de los trabajos de Freud y Lacan, el ordenamiento jerárquico de los genitales masculinos y femeninos es el resultado de la ley de la heterosexualidad obligatoria y la postergación de las mujeres (sin falo, castradas) frente a los hombres (los que tienen falo). Cuando el psicoanálisis demuestra que los componentes ordinarios de la personalidad femenina son "el masoquismo, el odio por uno mismo y la pasividad” (133), y propone al lesbianismo como un problema a curar, deja absolutamente en claro que el género es una construcción cultural, no un dato de la naturaleza.

La noción de género, por tanto, no coincide con lo biológico, sino que es una representación que no corresponde a un atributo del orden de la naturaleza, de allí la necesidad de gran parte de las teóricas feministas de desnaturalizar, desmontar, la creencia en una "esencia” femenina universal. En ese sentido, Teresa de Lauretis reconoce que si bien en los escritos feministas de la década del sesenta y el setenta la noción de género como diferencia sexual fue fundamental, el primer límite de este principio es que impide diferenciar a las mujeres al interior de "la" mujer. Es esto lo que afirma Nelly Richard cuando insiste en el aspecto semiótico-discursivo de la realidad, y subraya el carácter construido (representacional) de las marcas de identidad "masculino" y "femenino":

La demostración de cómo la identidad y el género sexuales son "efectos de significación" del discurso cultural que la ideología patriarcal ha ido naturalizando a través de su metafísica de las sustancias es útil para romper con el determinismo de la relación sexo (“mujer”)-género (“femenino”) vivida como relación plena, unívoca y transparente. Al movilizar la noción de género a través de toda una serie de desmontajes teóricos que muestran cómo dicha noción ha sido modelizada por convenciones ideológico-culturales, la crítica feminista nos permite alterar dichas convenciones reelaborando nuevas marcas 
de identificación sexual según combinaciones más abiertas que las antes seriadas por las normas de socialización dominante. (734-5)

En sintonía con la problemática de la identidad, la diferenciación genérica y sexual es pensada hoy también como una construcción híbrida y transitoria. Judith Butler habla así en contra del supuesto heterosexual dominante en la teoría literaria feminista. Dice entonces que el género es una construcción fantasmática armada sobre la repetición de una serie de rituales culturales, y el transformismo no hace sino mostrar la accidentalidad de esa construcción, la falta de sustancialidad de esos rótulos que utilizamos diariamente: “hombre”, “mujer”. Detrás de esos rótulos, sólo hay construcciones culturales, una red de discursos, dispositivos de poder. Una mujer es mujer en la medida en que funciona como mujer en la estructura heterosexual dominante. El terror, la angustia que sienten ciertas personas al "volverse gays", el miedo a perder el lugar que se tiene en el género, llevó a Butler en este sentido a constatar que la jerarquía sexual produce y consolida el género. Los límites de la no sustancia parecen detenerse entonces en el cuerpo como único soporte material. La "verdad” del sexo-como la llama con ironía Foucault-se produce justamente a partir de "prácticas reguladoras que generan identidades coherentes a través de la matriz de normas coherentes del género” (Butler 50). Apelar entonces a la categoría de performatividad permite dar cuenta justamente de que la sexualidad no es un acto único sino una repetición y un ritual, que logran ser efectivos mediante su naturalización en un cuerpo.

Podríamos decir entonces que, desde la lectura que se realiza desde el género, lo moderno implica la predominancia de la norma de lo masculino, en un sistema aparentemente horizontal de ciudadanía regida por "la ley del hermano” (Felski). Frente a esto, el debate posmoderno desmantela la noción de identidades fijas y da paso a una pluralidad de diferencias, donde el concepto operacional de "mujer" desaparece. Chantal Mouffe se pregunta en este sentido cómo puede contribuir una interpretación antiesencialista a la elaboración de una política feminista inspirada también en un proyecto democrático radical. Sólo cuando se deja de lado la visión de un sujeto al mismo tiempo racional, transparente y homogéneo se tiene la oportunidad de teorizar sobre las múltiples relaciones de subordinación. Mouffle reintroduce entonces la categoría de "posición de sujeto" para dar cuenta del agente social no ya como portador de una identidad única sino de una multiplicidad contradictoria, contingente y precaria, donde como sujeto puede ser dominante en una relación y subordinado en otra:

Este tipo de interpretación es sumamente importante para entender las luchas feministas, y también otras luchas contemporáneas. Su característica central es que un conjunto de posiciones de sujeto vinculadas por medio de su inscripción en las relaciones sociales, hasta ahora consideradas apolíticas, se han convertido en sitio de conflicto y antagonismo y ha dado lugar a la movilización política. (111)

La tesis de Mouffe al intentar reinscribir la política en la escena posmoderna es que en lo que respecta a la ciudadanía "la diferencia sexual no debe ser una distinción pertinente”, y que por lo tanto un proyecto de democracia radical y plural no necesita un 
modelo de ciudadanía sexualmente diferenciada. De lo que se trataría-y en esto coinciden, con matices y algunas diferencias, los artículos que hemos referido de Teresa de Lauretis, Gayle Rubin, Nelly Richard-es de construir un “nosotros” como ciudadanos democráticos radicales, "una identidad política colectiva articulada mediante el principio de equivalencia democrática” (121), una equivalencia que no anule las diferencias y donde lo contrario siempre será la identidad. De esta manera, Chantal Mouffe anuda la política feminista y la democracia radical y comprende al feminismo como la lucha por la igualdad de las mujeres, pero no entiende este grupo como un colectivo con esencia prefijada, sino más bien como una lucha en contra de las múltiples formas en que la categoría "mujer" se construye como subordinación.

Y es en este sentido que se puede pensar que las luchas feministas y la utilización del género como categoría de análisis cultural -en sintonía con las de raza y clase- deben reinscribirse en una teoría cultural que desmantele cualquier forma de subordinación, y dé cuenta de sus múltiples procesos de representación a partir de saberes localizados, en situación y en contra de cualquier instancia de dominación hegemónica en el mercado de bienes simbólicos.

Leer las marcas de género de la modernidad implica entonces reconstruir las representaciones y autorrepresentaciones con que las mujeres se inscriben como sujetos en la sociedad de la época. Desde esta perspectiva, el presente número de Revista Iberoamericana se inserta en la reflexión sobre los imaginarios femeninos en Latinoamérica en el esfuerzo por abordar los sentidos desplegados al interior de un conjunto de narrativas, fotografías, pinturas, diarios, autobiografías, sagas familiares, recuerdos de viaje, ensayos, al interior de los cuales las vicisitudes de lo femenino irrumpen bajo un ropaje cultural múltiple. Se trata de estudios que dialogan con escrituras de mujeres que trabajan, desde la literatura,los temas de la sexualidad y el poder; la memoria y la historia nacional; cuerpo y configuración territorial; la orfandad como punto de quiebre en la gestación de genealogías y proyectos políticos; la metáfora de la pérdida y la historia de los vencidos; las complicidades entre identidad, escritura, enfermedad; y las angustiosas zonas donde empalman placer sexual, dolor, vejez y muerte; entre otras líneas de reflexión. Por otro lado, este proyecto está enriquecido por ensayos que analizan imágenes de mujer construidas desde una escritura y una mirada masculina, fotografías que reinventan un nuevo archivo de la memoria afectiva, y pinturas que interrogan los temas del exilio, la migración y la identidad diaspórica.

El primer apartado, “Cicatrices”, tiene como eje la problemática del cuerpo femenino en contrapunto con la historia y la escritura: cuerpos supervivientes y replegados que arrastran consigo la historia de su tiempo, cuerpos contagiados que evidencian una inquietante contigüidad entre enfermedad y cuerpo letrado femenino, cuerpos de criminales y prostitutas que reconfiguran la geografía urbana, cuerpos migrantes que portan consigo las marcas del desarraigo y de las pérdidas. Ana María Amar Sánchez destaca los vínculos entre literatura, historia, política y ética en la narativa latinoamericana de los últimos cuarenta años. Asimismo analiza las resoluciones imaginarias de héroes y heroínas que encarnan una respuesta ética frente a las derrotas históricas latinoamericanas de las últimas décadas. En tal sentido se pregunta cómo los relatos escritos por mujeres representan la pérdida, la memoria, la resistencia, el duelo ante la imposibilidad de alcanzar alguna forma 
de heroísmo. La escritura es, entonces, una forma de acción en la que "el repliegue” deviene en figura clave que sustituye la afirmación del gesto antiheroico carecterístico de los relatos masculinos. Silvia Spitta se concentra en la obra pictórica de la artista cubana Sandra Ramos, abordando las tramas del exilio y la migración desde la mirada de quien se queda en la isla. Spitta asume la producción artística de Ramos como narrativa personal y política en el contexto cubano de una "época post-utópica”. Una narrativa que, con el horizonte del exilio, reinstala el tema de la nacionalidad como fetiche de consumo. Beatriz González Stephan explora las implicaciones entre cuerpo, enfermedad y sujeto letrado en Dolores (1869), de la escritora colombiana Soledad Acosta de Samper. González Stephan lee en el texto mencionado las tachaduras y secretos que el cuerpo letrado oculta para prohibir la configuración de una autoría femenina, en un mundo controlado por voces y géneros masculinos. Así, la literatura deviene en praxis social que contagia y modela subjetividades, soportado en el "poder metafórico de las letras". Adela Pineda trabaja la representación femenina del crimen, el espectáculo y la prostitución, en el ámbito de la literatura mexicana, como una "otra cara del imaginario porfiriano" del orden y el progreso. Pineda advierte en esta representación del cuerpo femenino una suerte de "necrología del espacio nacional” a la vez que una estetización del entramado social.

El segundo apartado, "De la fascinación”, se abre hacia una suerte de fenomenología del flirt, la mirada y la seducción. Los dos ensayos incluidos enfatizan -en el marco del siglo XIX- las relaciones entre género, ritual doméstico, discurso y política. Relaciones en las que desempeñan un papel fundamental la "gramática de la visión”, los juegos de ocultamiento y visibilidad, los espacios de intimidad y sociabilidad, y las transacciones entre deseo y política. Samuel Monder propone una sugerente lectura de los Recuerdos de viaje, de Eduarda Mansilla, enfatizando el flirt como clave del aparato retórico de la escritora. Monder fija su atención en las interrelaciones entre discurso, seducción y poder; destacando la institución del flirt como mediación entre los misterios de la alcoba y el discurso esteticista. Graciela Batticuore, por su parte, se refiere a las tertulias celebradas en la casa de una mujer ilustrada y patriota, Mariquita Sánchez de Thompson. El ensayo enfatiza el anudamiento entre las redes privadas y públicas, y entre género y política en la Argentina de la primera mitad del siglo xIx, los rasgos de una domesticidad mundana y culta, las complicidades entre historia nacional, familias patricias y la casa ilustrada como “espectáculo civilizador”.

"Itinerarios" incluye tres ensayos de aliento panorámico que realizan un recorrido enriquecedor a través de diversas geografías, escrituras, antologías, disciplinas y movimientos literarios. Así, los textos incluidos en este apartado registran analíticamente títulos y nombres de escritores que, en su articulación con proyectos político-culturales, posibilitan el trazado de un mapa genérico que incluye geografías generalmente poco conocidas en los espacios de circulación académica. Humberto Robles aporta un erudito trabajo sobre la representación de la mujer en Medardo A. Silva y José de la Cuadra, dos importantes escritores ecuatorianos representantes del modernismo y de la vanguardia, respectivamente. Robles nos acerca a la conformación de una idea e imagen de la mujer durante las décadas del veinte y del treinta considerando los paradigmas cosmopolitas y regionales, las relaciones culturales de clase, raza e identidad; los contrastes entre la mujer urbana/letrada/cosmopolita y la mujer rural/montuvia, y los múltiples discursos que 
coinciden en la esfera pública del agro y de la ciudad. A la vez, tiende puentes con los discursos y prácticas inscritos por el marxismo, el socialismo y el feminismo burgués que repercuten en el ámbito ecuatoriano de la época. Bárbara Dröscher explora un corpus representativo de la literatura escrita por mujeres en Centroamérica, entre 1975 y 2000, postulando como eje interpretativo el tropo de la orfandad. Dröscher propone la figura de la huérfana como metáfora de un quiebre en la reproducción de las construcciones tradicionales de los géneros, y como una ruptura simbólica de las genealogías. El estudio instala la figura de la huérfana en diálogo con los cambios sociales y culturales que han afectado y transformado en forma radical las sociedades centroamericanas durante la segunda mitad del siglo xx. Michael Handelsman ofrece al lector un balance crítico en torno a los aportes de la mujer a la tradición cuentística ecuatoriana. Handelsman reflexiona sobre tres antologías de narradoras ecuatorianas, publicadas entre 1997 y 2001, y se pregunta por el lugar que éstas ocupan en el imaginario nacional. Destaca aquí la centralidad de la mujer en la literatura ecuatoriana contemporánea, revalorando el lugar que las escritoras ocupan en la historia literaria del país. Este estudio aporta elementos que intersectan las antologías propuestas y las “mediaciones” culturales que han hecho posible la gestación y consolidación de nuevas escrituras e innovadores proyectos literarios.

“Memorias de la nación” presenta tres estudios que atienden a las complicidades entre escritura femenina y construcción del espacio público, memorias colectivas plurales e historia nacional, alianzas entre sexualidad y política, experiencia escrituraria femenina y metaficción historiográfica; todo ello en la certeza de que las memorias se encuentran entretejidas con el escenario social y ligadas a un sentido de pertenencia que conlleva, a la vez, un proceso de construcción y un espacio de lucha. Márgara Russoto asume el estudio de tres escritoras costarricenses, proponiendo una reflexión que anuda ensayo y escritura femenina en el contexto de la modernidad centroamericana. Russoto lee las escritoras seleccionadas -Yolanda Oreamuno, Eunice Odio y Carmen Naranjo- en contra de la tradicional idea en torno a la invisibilidad de las mujeres ensayistas. Los textos ensayísticos revelarían un gesto de doble politización: la desprivatización de la esfera privada y su irrupción en el espacio público desde una voluntad transgresora, en el marco de una modernización social que ha supuesto la transformación en la experiencia y funciones del género femenino. Susana Zanetti, por su parte, interpreta Doña Inés contra el olvido, de la escritora venezolana Ana Teresa Torres, asumiendo la memoria como el espacio de lucha contra el olvido, como una operación desde donde dar sentido al pasado. Así, la escritura de la novela busca polemizar con el lugar común según el cual la mujer escritora es una mera guardiana del pasado, una simple recopiladora de usos y costumbres. El estudio de Zanetti destaca precisamente las interrelaciones entre memorias colectivas e identidad nacional, y la participación activa de la memoria cuando, desde la escritura y la ficción histórica, interviene para diseñar un nuevo archivo de la nación y de las formas de intervención nacional. El trabajo de Juan Pablo Dabove se propone -a partir de la lectura de Cola de lagartija, de Luisa Valenzuela-indagar "la derivación monstruosa de las metáforas de identidad nacional”, el modo en que la novela elabora un romance nacional totalitario y la caracterización del devenir-monstruo del letrado. Dabove se pregunta qué le hace la mirada femenina a la representación de la nación cuando ésta es concebida como hombre, hombre-nación, hombre-monstruo. 
Los dos ensayos incluidos en "Interiores" conciben el ejercicio de escritura y memoria como acto de redención y “tributo a la existencia”; la escritura y la memoria, entonces, como espacios de supervivencia afectiva, como espacios habitados por la intimidad, la experiencia de lo sagrado, los procesos oníricos, la recuperación de la falta y las luchas contra el olvido. Gloria Medina se acerca al trabajo realizado conjuntamente por las artistas chilenas Diamela Eltit y Paz Errázuriz, El infarto del alma, para auscultar los intersticios y límites alojados en los lenguajes y archivos de la memoria. Medina se pregunta qué registra la mirada de una mujer, desde el ojo de una cámara y desde el ojo de una escritora, cuando se coloca en los confines de la razón y de la cultura. El infarto del alma es leído como testimonio del olvido social de sujetos marginales -los enfermos mentales- por el discurso dominante, y como archivo de la memoria afectiva, en el contexto del Chile (post) dictatorial. El texto de María Lúcia dal Farra analiza la novela de la escritora brasilera Adelia Prado, Manuscritos de Felipa (1999), poniendo especial atención a las caracteríasticas de una escritura abierta a la esfera cultural de lo femenino y a la búsqueda de una redención como mujer; una escritura percibida como proceso de construcción de una identidad y como terapia curativa. La crítica brasileña se pregunta por los modelos femeninos que subyacen en los manuscritos, estableciendo articulaciones entre escritura, miedos y clima apocalíptico como ejes clave de sentido.

En el último apartado, "Sexualidades”, se reúnen tres ensayos que inscriben una reflexión en torno a los anudamientos entre sexualidad y poder; cuerpos y espacios; deseo, identidad y escritura; los procesos de subjetivación y la configuración territorial. Florence Baillon lee la novela de la escritora colombiana Marvel Moreno, En diciembre llegaban las brisas, destacando las dinámicas urbanas en Colombia, la experiencia caribeña y el exilio parisino de la autora. Baillon se detiene ante la temática de la mirada, la problemática de los cuerpos como metáforas de campos de batalla y lugares de resistencia; en los efectos que provoca una sociedad patriarcal sobre los cuerpos y sobre la sexualidad femenina. Por su parte, Susan Canty Quinlan trabaja con dos obras de la escritora brasilera Lygia Fagundes Telles, desde una lectura que atiende a la problemática de las sexualidades otras, la ruptura con las visiones binarias en relación al género y la sexualidad, la temática de la identidad como "una categoría en crisis”, el deseo de placer sexual y los procesos de envejecimiento. Interroga, por último, las intersecciones entre intersexualidad e intertextualidad en el contexto de la cultura brasilera desde una óptica de mujer. Utilizando el concepto foucaultiano de "panóptico”, visto desde la perspectiva feminista, así como las nociones de fuga y desplazamiento, Teresa Peña estudia la novela de la escritora puertorriqueña Maruja Candal Salazar, La noche de Mercedes. Advierte y problematiza en la novela los límites del discurso feminista liberal en el contexto de la historia puertorriqueña, los procesos de subjetivación femenina en relación a una configuración territorial y biopolítica, los imaginarios de nacionalidad e insularismo característicos de las letras puertorriqueñas tradicionales, la temática de los miedos como dispositivo de control social y el trazado de una cartografía corporal cuyos límites aparecen siempre móviles y en permanente reelaboración.

En suma, los trabajos reunidos en el presente número hacen un aporte al saber en torno a los imaginarios femeninos a partir del recorrido por un mapa literario que entrelaza obras, nombres y narrativas representativas de México, Centroamérica, Cuba, Puerto 
Rico, Venezuela, Colombia, Ecuador, Argentina, Chile, Brasil. Las representaciones de mujer son múltiples y diversas, cambiantes y en permanente negociación, puesto que como afirma Judith Butler a propósito del género en disputa y de la construción cultural de la sexualidad “la ‘coherencia' y la ‘continuidad' de la 'persona' no son rasgos lógicos o analíticos de la calidad de persona sino, más bien, normas de inteligibilidad socialmente instituidas y mantenidas” (50). Así, este número ofrece imágenes de mujer que retratan heroínas perdedoras, exiliadas, criminales y prostitutas, damas ilustradas, seductoras/ traductoras, huérfanas liberadas, intelectuales, montuvias campesinas y letradas cosmopolitas, señoritas virginales y mujeres dueñas del deseo erótico, ensayistas, cimarronas, escritoras, travestidas, poseídas, emancipadas, madres y amantes; mujeres enfrentadas y en lucha pertinaz con la vejez, la muerte, el dolor, la historia, el olvido.

\section{Bibliografía}

Butler, Judith. El género en disputa. El feminismo y la subversión de la identidad. México: Paidós, 2001.

De Lauretis, Teresa. “The Technology of Gender”. Technologies of Gender: Essays on Theory, Film, and Fiction. Bloomington: Indiana University Press, 1987. 1-30.

Felski, Rita. The Gender of Modernity. Cambridge: Harvard University Press, 1995.

Foucault, Michel. The History of Sexuality. Vol.1. Robert Hurley, trad. New York: Vintage Books, 1980.

Mouffe, Chantal. "Feminismo, ciudadanía y política democrática radical”. El retorno de lo político: comunidad, ciudadanía, pluralismo, democracia radical. Barcelona, Buenos Aires, México: Paidós, 1999. 107-25.

Richard, Nelly. “Feminismo, experiencia, representación”. Revista Iberoamericana 176177 (julio-diciembre 1996): 733-44.

Rubin, Gayle. “El tráfico de mujeres: notas sobre la ‘economía política’ del sexo”. Nueva Antropología VIII/30 (México, 1986): 95-145. 